\title{
A PERSPECTIVA HISTÓRICO-DIALÉTICA DA PERIODIZAÇÃO DO DESENVOLVIMENTO INFANTIL
}

\author{
Juliana Campregher Pasqualini
}

\begin{abstract}
RESUMO. O presente artigo se propõe uma análise dos estágios do desenvolvimento infantil na perspectiva histórico-cultural. Nele são apresentados os princípios ou fundamentos que devem sustentar a periodização do desenvolvimento na perspectiva de Vigotski, buscando-se evidenciar o caráter histórico e dialético das proposições do autor. São também apontadas, de forma breve, algumas das importantes contribuições de Leontiev e Elkonin a essa temática. Discute-se inicialmente a importância de uma abordagem histórica do desenvolvimento da criança, enfatizando-se a relação criança-sociedade e as condições históricas concretas como determinantes do processo de desenvolvimento infantil. Em seguida, são apresentados os fundamentos da periodização das idades na perspectiva vigotskiana, destacando-se a relação entre as proposições do autor e os princípios do método dialético. São então apresentados os estágios do desenvolvimento infantil provisoriamente identificados por Vigotski e, por fim, a análise de Leontiev e Elkonin sobre a periodização do desenvolvimento apoiada na categoria de atividade principal.
\end{abstract}

Palavras-chave: desenvolvimento infantil, psicologia histórico-cultural, método dialético.

\section{HISTORIC-DIALECTICAL PERSPECTIVE ON CHILD DEVELOPMENT STAGES}

\begin{abstract}
This paper presents an analysis of the child development's stages under the historic-cultural perspective. The principles and fundamentals which should support periodization of child development according to Vigotski are presented, seeking to highlight the historical and dialectical character of his propositions. The paper also briefly presents Leontiev and Elkonin important contributions to this issue. Initially, the importance of an historic approach to child development is discussed, emphasizing the relationship between child and society and the concrete historic conditions as determiners of the child development process. Then, the fundamentals of age periodization in child development proposed by Vigotski are introduced, pointing the relationship between his propositions and the principles of the dialectical method. Next, the periods of child development provisionally identified by Vigotski are presented, followed by Leontiev and Elkonin analysis of periodization in child development from the category of main activity.
\end{abstract}

Key words: Child development, historic-cultural psychology, dialectical method.

\section{LA PERSPECTIVE HISTÓRICA-DIALÉCTICA DE LA PERIODIZACIÓN DEL DESARROLLO INFANTIL}

RESUMEN. El presente artículo propone un análisis del problema de los estadios del desarrollo psíquico en la infancia. Se presentan los fundamentos que deben sustentar la periodicidad del desarrollo en la perspectiva de Vigotski, buscándose evidenciar el carácter histórico y dialéctico de sus propuestas. Son también apuntadas algunas de las importantes contribuciones de Leontiev y Elkonin a esa temática. Se discute inicialmente la importancia de un enfoque histórico del desarrollo infantil, enfatizando la relación niño-sociedad y las condiciones históricas-concretas como determinantes del proceso del desarrollo infantil. En seguida, son presentados los fundamentos de la periodicidad de las edades en la perspectiva vigotskiana, marcando la relación entre las proposiciones del autor y los principios del método dialéctico. Se presentan los períodos del desarrollo infantil provisoriamente identificados por Vigotski y, por fin, el análisis de Leontiev y Elkonin sobre la periodicidad del desarrollo en la infancia apoyada en el concepto de actividad rectora..

Palabras-clave: Desarrollo en la infancia, psicología histórico-cultural, método dialéctico.

* Doutoranda do Programa de Pós-graduação em Educação Escolar da Universidade Estadual Paulista-UNESP, Araraquara. 
O desenvolvimento infantil tem sido objeto de diferentes análises e interpretações nas diversas abordagens da psicologia ao longo da história dessa ciência. A despeito da evidente diversidade de enfoques, na análise do psicólogo russo Daniil B. Elkonin (1987), é possível se identificar um elemento comum a grande parte das explicações sobre o processo de desenvolvimento da criança: o enfoque naturalista. Analisar o desenvolvimento infantil sob um enfoque naturalista significa, para o autor, compreender a criança como indivíduo isolado, para o qual a sociedade é apenas um peculiar "meio em que se habita" (p.110), bem como analisar o desenvolvimento psíquico meramente como um processo de adaptação às condições de vida.

Bock (2000) discute também a naturalização do fenômeno psicológico, a qual, em sua análise, referese à tentativa de explicar os fenômenos psíquicos a partir de uma suposta natureza do homem, apresentando como naturais e universais características social e historicamente constituídas. $\mathrm{O}$ psiquismo é, assim, tomado como um a priori no homem, ocultando-se sua determinação social e histórica. Afirma Bock (2000):

As características do desenvolvimento de nossas crianças e de nossos jovens têm sido tributadas à natureza humana, isto é, têm sido naturalizadas como características do desenvolvimento humano. A infância e a adolescência são pensadas como fases de um desenvolvimento esperado, previsto e natural. (p.27).

As fases do desenvolvimento são, assim, concebidas como partes de um "ciclo vital" universal e idêntico para todos os homens. Torna-se possível, nessa perspectiva, estabelecerem-se fases e estágios de desenvolvimento que, embora possam sofrer alguma influência das interações sociais, sucedem-se numa ordem fixa, válida para todo e qualquer indivíduo em todo e qualquer contexto e a qualquer tempo. O desenvolvimento percorreria, assim, um caminho natural e espontâneo.

A Psicologia Histórico-Cultural, que tem em Vigotski, Leontiev, Luria e Elkonin alguns de seus principais representantes, nega a possibilidade de se analisar o desenvolvimento psicológico infantil como um processo meramente natural, caracterizado por fases ou estágios que se sucederiam em uma ordem fixa e universal. Essa negação, contudo, não levou essa vertente da psicologia a abandonar ou secundarizar o problema da periodização do desenvolvimento.
A elaboração do problema dos estágios ou períodos do desenvolvimento infantil, na análise de Elkonin (1987), tem grande importância teóricoprática, na medida em que elucida a questão da sensibilidade de determinados períodos do desenvolvimento a determinados tipos de influência educativa, bem como implica compreender as leis de transição de um período a outro do desenvolvimento da criança - e, portanto, as forças motrizes do desenvolvimento psíquico. Ademais, Elkonin (1987) considera que a correta solução do problema da periodização do desenvolvimento tem como significado prático embasar o (re)planejamento dos sistemas de educação e ensino das novas gerações, desafio que se colocava para a sociedade soviética com o advento da Revolução Socialista de 1917 - e que não deixa de estar posto em nossa sociedade.

Assim, pretendemos apresentar os princípios ou fundamentos que, na perspectiva de Vigotski, devem sustentar a periodização do desenvolvimento infantil, procurando evidenciar o caráter histórico e dialético das proposições do autor. Buscaremos também, ainda que de forma breve, apresentar algumas das contribuições de Leontiev e Elkonin à compreensão da periodização do desenvolvimento.

\section{A ABORDAGEM HISTÓRICA DO DESENVOLVIMENTO INFANTIL}

A tentativa da ciência psicológica de encontrar características e leis universalmente válidas para o desenvolvimento infantil foi objeto da crítica de Vigotski (2001): "a tarefa da psicologia consiste justamente em revelar não o eterno infantil mas o historicamente infantil (...)" (p.96). Vygotski (1995) considerava inteiramente equivocado o ponto de vista das diversas vertentes da psicologia vigentes em sua época, que supunha como equivalentes e idênticos o funcionamento psíquico e a concepção de mundo de “(...) uma criança européia de família culta dos dias de hoje e uma criança de alguma tribo primitiva, (...) da criança da Idade da Pedra, da Idade Média ou do século XX (...)" (p.22). Na análise do autor, a psicologia tradicional estudava a criança e o desenvolvimento de suas funções psíquicas à margem de seu meio social e cultural, desconsiderando as formas de pensamento e concepções predominantes nesse meio.

Elkonin (1987) chama a atenção para a importância de um enfoque histórico do processo de desenvolvimento, revelando que certos estágios do desenvolvimento infantil delineiam-se no curso da história da humanidade, com a alteração do lugar 
ocupado pela criança nas sociedades. Sua análise acerca da origem histórica do jogo protagonizado ilustra com clareza essa tese. Apoiado em estudos antropológicos e etnográficos, Elkonin (1998) demonstra que o jogo de papéis é muito raramente observado em comunidades primitivas e mesmo em sociedades de economia baseada em formas rudimentares de agricultura e pecuária, nas quais as crianças são precocemente integradas ao trabalho dos adultos $^{1}$. O autor conclui que a origem desse jogo está relacionada à mudança do lugar ocupado pela criança na vida das sociedades - fundamentalmente no que se refere a seu afastamento da atividade produtiva.

Tratando especificamente de sociedades com formas relativamente mais avançadas de produção, como agricultura e pecuária, nas quais se verifica uma maior complexidade das ferramentas, Elkonin destaca a existência de ferramentas confeccionadas em tamanho reduzido, que são entregues às crianças para que se exercitem e aprendam seu manejo. Dessa forma,

\begin{abstract}
A reconstituição da atividade dos adultos em condições lúdicas especiais carece de todo o sentido, em virtude da identidade das ferramentas que utilizam as crianças e os mais velhos, bem como da gradual aproximação das condições de seu emprego às situações concretas de trabalho (Elkonin, 1998, p.75).
\end{abstract}

Assim, Elkonin (1998) evidencia que o jogo protagonizado aparece historicamente em função da complexificação das forças produtivas, que vai tornando o trabalho dos adultos inexequíivel para a criança, afastando-a da esfera produtiva e das atividades dos adultos e exigindo um período de preparação especial para o trabalho e para a vida adulta. É possível afirmar que os jogos de papéis surgem como um modo peculiar de penetração na esfera da vida e relações adultas interditas para as crianças, determinando o delineamento de um novo período no desenvolvimento infantil, que recebeu, na psicologia infantil, o nome de período do desenvolvimento pré-escolar.

Fica clara, assim, a necessidade de considerar na investigação do desenvolvimento infantil o vínculo

1 Cabe esclarecer que a participação da criança no trabalho produtivo do adulto não configurava, nessas sociedades, exploração do trabalho infantil, tendo caráter de tarefa social espontânea. Os adultos não castigavam as crianças e procuravam garantir que estivessem alegres; as crianças, por sua vez, mostravam-se satisfeitas por ter atuado com os adultos e como adultos (Elkonin, 1988). entre criança e sociedade, ou o lugar que a criança ocupa no sistema das relações sociais em cada momento histórico, pressuposto que também está presente na obra de Leontiev (2001). Ao discutir a questão dos estágios de desenvolvimento do psiquismo infantil, o autor afirma que nem o conteúdo dos estágios nem sua seqüência no tempo são imutáveis e dados de uma vez por todas, visto que o conteúdo dos estágios é determinado pelas condições históricas concretas. Assim, não é a idade da criança que determina o conteúdo do estágio do desenvolvimento, mas “os próprios limites de idade de um estágio, pelo contrário, dependem de seu conteúdo e se alteram pari passu com a mudança das condições histórico-sociais" (p.65-66).

Nesse sentido, vemos que Vigotski, Leontiev e Elkonin concebiam o desenvolvimento infantil como fenômeno histórico não determinado por leis naturais universais, mas intimamente ligado às condições objetivas da organização social, sendo fundamental considerar o lugar ocupado pela criança nas relações sociais e as condições históricas concretas em que seu desenvolvimento se desenrola.

\section{FUNDAMENTOS DIALÉTICOS DA PERIODIZAÇÃO DO DESENVOLVIMENTO EM VIGOTSKI}

Vygotski (1995) refuta a compreensão do desenvolvimento infantil como um processo estereotipado de crescimento e maturação de potências internas previamente dadas, perspectiva conhecida como pré-formismo. Tal concepção remete à analogia entre o desenvolvimento infantil e os processos de crescimento das plantas, reduzindo o complexo processo de desenvolvimento psíquico a determinações quase exclusivamente biológicas. Ao contrário, Vygotski (1995) explicita a subordinação dos processos biológicos ao desenvolvimento cultural, demonstrando que “(...) a cultura origina formas especiais de conduta, modifica a atividade das funções psíquicas, edifica novos níveis no sistema do comportamento humano em desenvolvimento" (p.34).

Essa relação entre biológico e cultural fica especialmente clara na análise de Vygotski (1995) acerca do desenvolvimento das funções psicológicas. $\mathrm{O}$ autor diferencia as funções psicológicas elementares, comuns a homens e animais (tais como atenção e memória involuntárias) das funções exclusivamente humanas, que denominou funções psicológicas superiores (tais como a atenção voluntária, a memória mediada e o pensamento abstrato). As funções superiores têm gênese 
fundamentalmente cultural - e não biológica. $\mathrm{O}$ autor não estabelece, contudo, uma dicotomia entre as funções elementares e superiores; afirma que as formas inferiores não se aniquilam, mas continuam existindo como instância subordinada às funções superiores. As relações entre as funções elementares e superiores explicam-se, na análise de Vygotski (1995), por meio da categoria de superação, uma importante categoria do método dialético:

Hegel disse que é preciso recordar o duplo significado da expressão alemã 'snimat (superar)'. Entendemos esta palavra em primeiro lugar como 'ustranit-eliminar', 'otritsat-negar', e dizemos, dessa forma, que as leis estão anuladas, 'uprazdnenisuprimidas'; mas esta mesma palavra significa também 'sojranit-conservar' e dizemos que algo 'sojranim-conservaremos'. $\mathrm{O}$ duplo significado do termo 'snimatsuperar' se transmite habitualmente bem no idioma russo com a ajuda da palavra 'sjoronit-esconder ou enterrar', que também tem sentido negativo e positivo - destruição ou conservação. Utilizando essa palavra, poderíamos dizer que os processos elementares e as leis que os regem estão enterradas na forma superior do comportamento, isto é, aparecem nela subordinadas e ocultas (p.117-8).

Outro problema apontado por Vygotski (1996) na psicologia tradicional era a tentativa de encontrar nos sintomas ou indícios externos do desenvolvimento infantil os fundamentos da periodização das idades. $\mathrm{O}$ autor postula que os fundamentos dessa periodização devem ser buscados não nos indícios externos, ou seja, no conjunto de sintomas que diferenciam os diversos períodos, fases e/ou estágios, mas nas mudanças internas do processo de desenvolvimento infantil. Vygotski (1996) buscava uma periodização baseada na essência ou nas particularidades essenciais do processo de desenvolvimento psicológico: “(...) devemos renunciar a todas as tentativas de classificar as idades por sintomas e passar, como fizeram a seu tempo outras ciências, a uma periodização baseada na essência interna do processo estudado" (p.253).

Para Vygotski (1996), portanto, a apreensão da realidade pelo pensamento não se realiza de forma imediata, pelo contato direto com a aparência dos fenômenos. $\mathrm{O}$ autor considera, em consonância com o método histórico-dialético, que as manifestações externas do fenômeno não expressam seu "núcleo interno essencial” (Kosik, 1976, p.10): “(...) na realidade a essência interna dos objetos e sua manifestação externa não coincidem" (Vygotski,
1996, p.253). Assim como Marx (1983, p.271), para quem "(...) toda ciência seria supérflua se a forma de aparecimento e a essência das coisas coincidissem imediatamente", Vigotski considerava, como já apontado por Duarte (2000), que a apreensão da realidade pelo pensamento implica a mediação de abstrações teóricas.

Nesse sentido, em oposição a uma análise meramente descritiva, Vygotski (1996) defende uma análise psicológica explicativa, que revele os nexos dinâmico-causais que determinam a origem e desenvolvimento dos fenômenos. A verdadeira tarefa na investigação das etapas do desenvolvimento psicológico consiste “(...) em investigar o que se oculta por trás dos sintomas, aquilo que os condiciona, isto é, o próprio processo de desenvolvimento infantil com suas leis internas" (p.253). Cumpre ressaltar que o caráter interno desse processo não remete a um caráter biológico, mas ao fato de que cada avanço no desenvolvimento está diretamente determinado por aquilo que se formou na etapa anterior.

Um conceito fundamental para o estudo do desenvolvimento infantil na perspectiva vigotskiana é a noção de estrutura da idade: em cada idade, a multiplicidade dos processos parciais que integram o processo de desenvolvimento constitui um todo único e possui uma determinada estrutura. A estrutura de cada idade é específica, única e irrepetível, e determina o papel e o peso específico de cada linha parcial do desenvolvimento ${ }^{2}$. Isso significa que não se verificam modificações em aspectos isolados da personalidade da criança, mas, ao contrário, modificase a estrutura interna da personalidade como um todo. Vygotski (1995) contrapõe-se, assim, à análise atomística em psicologia, que decompõe os processos psíquicos em elementos que são estudados

Vale aqui destacar que o termo estrutura assume uma acepção diversa daquela presente na teoria piagetiana. Vigotski (1996) refere-se à estrutura da idade como uma formação global, que integra, em cada período, a multiplicidade dos processos parciais de desenvolvimento, tais como percepção, memória, atenção, linguagem etc. $\mathrm{O}$ autor busca evidenciar, dessa forma, que as transformações não se operam nos processos psíquicos parciais de modo isolado, mas que o psiquismo da criança se modifica em sua estrutura interna como um todo, tendo em vista, portanto, uma perspectiva de totalidade. Piaget (1967), por sua vez, refere-se às estruturas da inteligência como "as formas de organização da atividade mental” (p.13). A cada estágio do desenvolvimento, segundo o autor, encontramos um tipo de estrutura que caracteriza todos os comportamentos novos próprios dessa fase. Dessa forma, as estruturas cognitivas na ótica piagetiana podem ser entendidas como padrões de organização das ações físicas e mentais subjacentes aos atos de inteligência. 
isoladamente. Para ele, a tarefa fundamental da análise psicológica “(...) não é decompor o todo psicológico em partes ou fragmentos, mas destacar do conjunto psicológico integral determinados traços e momentos que conservam a primazia do todo" (p.99-100). Esse princípio remete à relação todo-parte e à categoria de totalidade no método dialético, segundo o qual os "fatos são conhecimento da realidade se são compreendidos como fatos de um todo dialético - isto é, se não são átomos imutáveis, indivisíveis e indemonstráveis, de cuja reunião a realidade seja constituída - se são entendidos como partes estruturais do todo." (Kosik, 1976, p.36).

Dessa forma, Vygotski (1996) postula que se deve investigar o novo tipo de estrutura da personalidade e da atividade da criança, as mudanças psíquicas e sociais que se produzem pela primeira vez em cada idade e determinam a consciência da criança e sua relação com o meio. Em cada etapa do desenvolvimento infantil, para o autor, encontra-se sempre uma nova formação central, que constitui uma espécie de guia para todo o processo de reorganização da personalidade da criança. Diferenciam-se, nesse processo, as linhas centrais do desenvolvimento - que se referem aos processos diretamente relacionados a essa nova formação específica da idade - e as linhas acessórias, que estariam ligadas aos processos secundários. Cabe ressaltar que os processos constitutivos das linhas principais de desenvolvimento em uma idade convertem-se em linhas acessórias na fase seguinte, e o oposto também é verdadeiro.

Assim, as funções psíquicas não se desenvolvem de maneira proporcional e uniforme, mas cada idade tem sua função predominante - sendo que as funções mais importantes, que servem de fundamento a outras, desenvolvem-se primeiro. A função básica de cada idade encontra-se em condições sumamente propícias para seu desenvolvimento. Na primeira infância, por exemplo, a função psicológica básica é, para Vygotski (1996), a percepção, como veremos adiante; esse será o período propício para o desenvolvimento da percepção verbal. Nesse sentido, a psicologia pode subsidiar a organização do ensino ao identificar o que Vygotski (1996) denomina de prazos ótimos da aprendizagem - o período mais propício e produtivo para determinado tipo de aprendizagem. Esse conceito remete a outro de extrema importância na obra de Vygotski (1996): a zona de desenvolvimento proximal (ZDP), que é definida como "a esfera dos processos imaturos, mas em vias de maturação" (p.269). O período mais propício para o desenvolvimento de uma determinada função psicológica é justamente aquele em que ela se encontra em processo de maturação.
Nesse sentido, torna-se importante compreender a dinâmica do aparecimento das novas formações. A dinâmica do desenvolvimento refere-se ao conjunto de todas as leis que regulam a formação e as mudanças das novas estruturas em cada idade, e sua compreensão implica a análise das relações entre a personalidade da criança e seu meio social naquela etapa do desenvolvimento: trata-se do conceito de situação social de desenvolvimento (Vygotski, 1996, p.264). Para Vygotski (1996), “(...) a realidade social é a verdadeira fonte de desenvolvimento (...) (p.264). Assim, a situação social de desenvolvimento se refere à relação que se estabelece entre a criança e o meio que a rodeia - que é peculiar, específica e irrepetível em cada etapa do desenvolvimento. Ela constitui o ponto de partida para todas as mudanças dinâmicas que se processarão durante aquela idade, na medida em que determina "plenamente e por inteiro" (idem, p.264) as formas e a trajetória que permitem à criança adquirir novas propriedades da personalidade.

A lei fundamental que rege a dinâmica das idades, para Vygotski (1996), consiste em que as forças que movem o desenvolvimento da criança de uma idade a outra acabam por negar e destruir a própria base do desenvolvimento da idade anterior, determinando, como necessidade interna, o fim da situação social de desenvolvimento, ou seja, o fim da etapa vigente em direção à etapa seguinte. Assim, o desenvolvimento das novas formações que surgem ao final de uma determinada idade "(...) mudam toda a estrutura da consciência infantil, modificando assim todo o sistema de sua relação com a realidade externa e consigo mesma" (p.265). A estrutura modificada da consciência da criança determina a "reconstrução de sua vida" (p.264), pois a criança, na verdade, "já é outra criança" (p.264). A situação social de desenvolvimento na primeira infância, por exemplo, caracteriza-se pela total dependência da conduta em relação à situação presente. Com o desenvolvimento da linguagem, como nova formação desse período (que determinará o surgimento da consciência), rompese a unidade sensório-motora, ou seja, a unidade entre percepção e ação, e modifica-se a relação da criança com seu entorno, portanto, o próprio caráter da influência desse entorno sobre a criança: "a situação social de desenvolvimento, existente no começo da idade, se modifica, e uma vez que a criança se faz distinta, se destrói a velha situação social de desenvolvimento e começa um novo período de idade" (Vygotsi,, 1996, p.350).

Para Vygotski (1996), o desenvolvimento caracteriza-se pela alternância de períodos estáveis e 
críticos. Nos períodos estáveis, o desenvolvimento se deve principalmente a mudanças "microscópicas" da personalidade da criança, que vão se acumulando até certo limite e se manifestam mais tarde como uma repentina formação qualitativamente nova. Nos períodos de crise, produzem-se mudanças e rupturas bruscas e fundamentais na personalidade em um tempo relativamente curto, culminando em uma reestruturação das necessidades e motivos da criança e de sua relação com o meio. Verifica-se aqui a adoção do princípio do método dialético da transformação da quantidade em qualidade: o acúmulo quantitativo culmina no salto qualitativo. Conforme Prado Jr. (1969), na dialética o desenvolvimento dos fenômenos

(...) passa de mudanças quantitativas insignificantes e latentes a mudanças aparentes e radicais, a mudanças qualitativas; onde as mudanças qualitativas não são graduais, mas rápidas e súbitas, e se operam por saltos, de um estado a outro; estas mudanças não são contingentes, mas necessárias; resultam da acumulação de mudanças quantitativas insensíveis e graduais (p.602).

Assim, fica claro que o desenvolvimento é um processo dialético, em que a passagem de um estágio a outro se realiza não por via evolutiva, mas sim, revolucionária.

Por fim, destacamos a importância fundamental atribuída por Vygotski (1996) ao afeto, que é considerado pelo autor como fator essencial do desenvolvimento psíquico em todas as suas etapas e concebido em unidade com - e não em oposição a - o intelecto: “(...) o afeto e o intelecto não são dois pólos reciprocamente excludentes, mas duas funções psíquicas estreitamente vinculadas entre si e inseparáveis" (p.314).

A partir de suas investigações, Vigotski propõe, ainda que provisoriamente, uma periodização das fases do desenvolvimento psicológico, composta pelas seguintes idades: crise pós-natal; primeiro ano de vida; crise do $1^{\circ}$ ano; primeira infância; crise dos três anos; idade pré-escolar; crise dos sete anos; idade escolar; crise dos 13 anos; puberdade e crise dos 17 anos. Abordaremos cada período do desenvolvimento analisado por Vygotski (1996) até a crise dos sete anos, apoiando-nos nos manuscritos produzidos nos últimos anos de sua vida (1932 a 1934) e na transcrição de conferências proferidas entre 1933 e 1934, que compõem a obra Problemas de la psicologia Infantil.

\section{OS PERÍODOS DO DESENVOLVIMENTO INFANTIL SEGUNDO VIGOTSKI}

Vygotski (1996) descreve inicialmente o período pós-natal, considerado uma etapa crítica de uma transição ente o desenvolvimento intra e extra-uterino. A nova formação central e básica desse período é o que Vigotski denomina vida psíquica individual do recém-nascido: uma vida psíquica primitiva, especifica desse período, que não se conserva como tal nos períodos posteriores, mas integra-se como instância subordinada às formações nervosas e psíquicas de nível superior. A vida psíquica individual do bebê fundamenta-se na separação do bebê do organismo da mãe, convertendo sua existência em individual, e caracteriza-se pela fusão de sensação e afeto, indistinção de objetos sociais e físicos, passividade e ausência de vivência social.

A etapa denominada de primeiro ano por Vigotski (1996) inicia-se entre o final do primeiro mês e início do terceiro, quando se verifica uma transformação no estado psíquico e social da criança em função de mudanças no ciclo de sono e alimentação. Aparecem na criança as primeiras reações propriamente sociais, como o sorriso quando ouve a voz humana ou o choro quando ouve outra criança chorar. A situação social do bebê caracterizase pela contradição entre, por um lado, sua máxima sociabilidade - pois em função de sua completa dependência dos adultos, toda a relação do bebê com a realidade circundante é socialmente mediada - e por outro, suas mínimas possibilidades de comunicação. Pode-se afirmar, de acordo com Vigotski, que no início dessa fase o mundo exterior "surge" para a criança, visto que para ela no período pós-natal não existe "nada nem ninguém" (Vygotski, 1996, p.306) e ela não é capaz de diferenciar-se do mundo exterior. Assim é possível identificar três estágios durante o primeiro ano, referentes à relação da criança com o meio social: os períodos de passividade, de interesse receptivo e de interesse ativo. Tais períodos marcam a passagem gradual da passividade à atividade. Ainda segundo o autor, o afeto é o processo central responsável pela unidade entre as funções sensoriais e motoras que caracteriza esse período.

Com a primeira utilização de instrumentos e o emprego de palavras para expressar desejos, começa um novo período, que marca a crise do primeiro ano. O início e o fim da crise do primeiro ano de vida são marcados pelo início e o fim do que se denomina linguagem autônoma infantil. Embora se trate de uma tese ainda pouco elaborada pelo autor, Vygotski (1996) afirma ser esta a provável nova formação da crise do primeiro ano, de caráter transitório, como é 
característico das novas formações dos períodos de crise. A linguagem autônoma infantil não coincide com a linguagem adulta nem quanto aos aspectos articulatório e fonético nem no que se refere à coesão e à atribuição de significado. Uma de suas peculiaridades é que as crianças utilizam uma única palavra para se referir a todo um conjunto de coisas que os adultos designam com palavras diferentes. As palavras utilizadas pelas crianças são em geral "retalhos" das palavras da linguagem adulta. Como verificado em um experimento realizado por Vygotski (1996), a criança pode utilizar a mesma palavra para se referir a até onze objetos diferentes sem relação direta entre si (p.ex.: pato, água, leite, garrafa etc.). O critério para que objetos estejam incluídos em um mesmo significado pode remeter a propriedades físicas semelhantes (ex: cor, sabor, textura), proximidade no espaço (ex: pato e água) ou mesmo à similitude sonora das palavras utilizadas pelos adultos para nomear tais objetos. Por esse motivo, a comunicação com as crianças através dessas palavras só é possível em situações concretas, pois seu significado não é constante, mas situacional. As palavras da linguagem autônoma não representam ou substituem o objeto, apenas o indicam; têm, portanto, a função de indicar e denominar, mas carecem da função significadora.

Quando se forma, então, na criança o que Vigotski (1996) denomina linguagem autêntica, desaparece a linguagem autônoma e se encerra o período crítico, iniciando-se a primeira infância. Os dois principais fatos novos que aparecem nessa etapa, para Vigotski, são a percepção generalizada dos objetos (ou percepção semântica) e o desenvolvimento da linguagem. A linguagem representa a linha central de desenvolvimento dessa idade, pois graças a ela a criança estabelece com o meio social relações distintas daquelas que estabelecia até então; mas tanto o desenvolvimento da percepção quanto o da linguagem estão estreitamente vinculados entre si nesse período.

A princípio, a criança é inteiramente dependente do campo visual-direto; há uma unidade entre a percepção afetiva e a ação: cada percepção da criança é seguida por uma ação. O que caracteriza a situação social da criança é a dependência da situação. Com o desenvolvimento da linguagem, modifica-se a estrutura da percepção: a percepção sem palavras vai sendo substituída pela percepção verbal, dotada de sentido, convertendo-se em percepção generalizada. Com o surgimento das generalizações no campo da linguagem, a criança passa a perceber os objetos no interior de um todo que possui, para além de suas propriedades físicas, um determinado sentido social.
Sendo a percepção a função básica dessa idade, ela se encontra, segundo Vygotski (1996), em condições sumamente propícias para o seu desenvolvimento. A partir dos apontamentos sobre o desenvolvimento da linguagem e da percepção, o autor afirma que a nova formação central dessa idade é o surgimento da consciência. Para Vygotski (1996), dizer que o homem atua conscientemente é o mesmo que dizer que suas ações são imbuídas de sentido, e pela primeira vez é possível identificar na conduta da criança a compreensão verbal dos objetos e de sua própria conduta.

O período seguinte no processo de desenvolvimento é a crise dos três anos. Vygotski (1996) esclarece que sua teorização a respeito dessa crise tem um caráter inicial. De modo geral, ela caracteriza-se por um conjunto de sintomas, quais sejam: a) negativismo; b) teimosia; c) rebeldia e d) insubordinação. O negativismo refere-se ao fato de a conduta da criança opor-se a tudo o que lhe propõem os adultos - ressaltando-se que não se trata de uma reação ao conteúdo específico das solicitações ou proposições, mas ao fato mesmo de tal solicitação ter sido feita pelo adulto. A teimosia refere-se à atitude da criança de insistir em ser atendida em suas exigências, destacando-se que tal insistência não se deve ao desejo intenso da criança de obter algo, mas ao fato de querer ser atendida em algo que ela disse ou exigiu anteriormente (tendência voltada a si mesma, e não ao outro - o adulto, como no caso do negativismo). A rebeldia é uma atitude de protesto generalizado, dirigido não a pessoas (como no caso do negativismo), mas às normas educativas e ao regime de vida imposto à criança. Por fim, a insubordinação refere-se à aspiração da criança de ser independente e querer fazer tudo por si mesma. Além desses, são descritos pelo autor outros sintomas secundários, a saber: protesto violento, despotismo e ciúmes. Todos esses sintomas, para Vygotski (1996), "giram em torno do 'eu' e das pessoas que o rodeiam" (p.373), retratando a crescente independência e atividade da criança e demonstrando que suas relações com as pessoas à sua volta ou com sua própria personalidade já não são as mesmas de antes.

Modifica-se a relação da criança com seus próprios afetos e ela já é capaz de agir contra seus próprios desejos. Nesse sentido, Vygotski (1996) relata uma situação experimental na qual, pelo imperativo de contrapor-se ao adulto, a criança foi capaz de recusar um convite para um passeio, mesmo tendo anteriormente expressado o desejo de fazê-lo simplesmente porque o convite foi feito pelo adulto. Trata-se de uma grande conquista da criança, que revela não ser ela mais totalmente dominada pelo afeto (no exemplo, o desejo de fazer o passeio), como 
ocorria na primeira infância, em função unidade entre afeto e atividade; agora, o motivo de sua reação já não tem necessariamente relação direta com o conteúdo da situação presente.

Vygotski (1996) não discute formas consideradas adequadas para lidar com os sintomas da crise dos três anos, limitando-se a alertar para o fato de que a criança durante essa fase crítica pode ser "difícil de educar" (p.372). O autor sinaliza também a possibilidade do surgimento de "complicações da crise dos três anos" (p.374), que podem levar ao desenvolvimento de condições patológicas. Cabe destacar aqui a importância do conhecimento desse processo de reestruturação interna da personalidade para o educador que atua junto a crianças nessa faixa etária, pois o desconhecimento pode conduzi-lo a atitudes inadequadas, que, ao invés de promoverem o desenvolvimento infantil no sentido de fortalecer sua independência e autonomia, podem contribuir para conduzir a criança às "complicações" a que se referiu Vigotski.

O período seguinte à crise dos três anos é, na periodização proposta pelo autor, a idade pré-escolar. Não há, no entanto, um capítulo dedicado a essa etapa do desenvolvimento ${ }^{3}$. O capítulo seguinte à discussão sobre a crise dos três anos refere-se à crise dos sete anos. Para Vygotski (1996), a principal característica dessa crise é o que ele denomina de perda da espontaneidade infantil. Segundo ele, a criança préescolar é espontânea porque nela não se diferenciam suficientemente a vida interior e a exterior - a criança se manifesta externamente tal como ela é "por dentro". Em linhas gerais, pode-se afirmar que "a perda da espontaneidade significa que incorporamos à nossa conduta o fator intelectual que se insere entre a vivência e o ato direto" (p.378). Com a crise dos sete anos, a criança passa a ser capaz de julgar a si mesma e a valorar sua posição no contexto social. A partir desse período as vivências da criança adquirem sentido - o que significa que a criança que está chateada agora é consciente de que está chateada. Dessa forma, tornam-se possíveis novas relações da criança consigo mesma.

\section{A CONTRIBUIÇÃO DE LEONTIEV E ELKONIN}

As proposições de Vigotski sobre a periodização do desenvolvimento têm caráter declaradamente inacabado. Devido a sua morte prematura, não foi

\footnotetext{
3 Vigotski abordou essa temática no artigo Play and its role in the mental development of the child (disponível no endereço eletrônico http://www.marxists.org/archive/vygotsky/1933/play.htm).
}

possível ao autor concluir sua teoria do desenvolvimento psíquico; contudo, suas proposições constituem um evidente esforço de construção de categorias e de uma metodologia de análise do desenvolvimento infantil na perspectiva históricodialética.

Para Facci (2004), "Leontiev e Elkonin, seguindo a linha sócio-histórica ou histórico-cultural iniciada por Vigotski, desenvolveram as bases de uma psicologia do desenvolvimento que superasse o enfoque naturalizante tão forte nesse campo.” (p.64). Os autores abordam a questão da periodização a partir do pressuposto de que cada estágio do desenvolvimento infantil seria caracterizado por uma atividade principal. Não se trata da atividade que ocupa mais tempo na vida da criança naquele período, mas daquela no interior da qual surgem e se diferenciam outros tipos de atividade, na qual os processos psíquicos particulares tomam forma ou são reorganizados e da qual dependem, de forma mais íntima, as mudanças mais importantes nos processos psíquicos e traços psicológicos da criança naquele estágio (Leontiev, 2001).

A partir da categoria de atividade principal, Leontiev (2001) aponta a brincadeira infantil, a atividade de estudo e o treinamento especial ulterior ou o trabalho como “(...) a sucessão das atividades [principais] e das relações que podemos notar em nossas condições na URSS" (p.66) ${ }^{4}$. Elkonin (1987) avança nas investigações e apresenta uma caracterização mais detalhada das épocas e períodos do desenvolvimento infantil desde o nascimento até a juventude. Segundo seu esquema de periodização, temos a época da primeira infância, constituída pelo período da comunicação emocional direta com os adultos, seguido da atividade objetal manipulatória; a época da infância caracterizada pelo jogo de papéis (na idade pré-escolar) e pela atividade de estudo (na idade escolar) e a adolescência, constituída pelo período da comunicação íntima pessoal, seguida pela atividade profissional e de estudo (Elkonin, 1987, p.122).

Na análise de Davidov (1988), o conceito de atividade principal adotado por Leontiev é análogo ao conceito de situação social de desenvolvimento de Vigotski. A situação social de desenvolvimento, como

\footnotetext{
4 O autor analisa, ainda, a transição a um novo tipo de atividade principal a partir dos elementos que, em sua análise, constituem a estrutura da atividade humana. A reconstrução de ações e operações se dá no interior de cada estágio do desenvolvimento, criando condições para a mudança de atividade principal, que caracteriza a transição a um novo estágio.
} 
vimos, refere-se à relação que se estabelece entre a criança e o meio que a rodeia, que é peculiar, específica, única e irrepetível em cada idade ou estágio do desenvolvimento. Para Davidov (1988), a aproximação entre os dois conceitos fica evidente ao considerarmos que a situação social de desenvolvimento se refere, antes de tudo, à relação da criança com a realidade social, tendo em vista que essa relação se realiza precisamente por meio da atividade humana.

Assim, se para Vygotski (1996) as forças motrizes do desenvolvimento da criança acabam por negar e destruir a própria base do desenvolvimento da idade anterior, determinando, como necessidade interna, o fim da situação social de desenvolvimento vigente em direção à etapa seguinte, na análise de Leontiev (2001) a mudança de atividade principal ocorre quando "surge uma contradição explícita entre o modo de vida da criança e suas potencialidades, as quais já superaram este modo de vida. De acordo com isso, sua atividade é reorganizada e ela passa, assim, a um novo estágio no desenvolvimento de sua vida psíquica." (p.66).

Em relação ao papel das crises na transição de um a outro estágio do desenvolvimento, Elkonin (1987) afirma que "introduzindo estes momentos de crise no esboço dos períodos do desenvolvimento infantil obtemos o esquema geral de periodização da infância em épocas, períodos e fases 5 ", (p.123). Leontiev (2001), por sua vez, corrobora a visão de Vigotski sobre as mudanças e saltos qualitativos que caracterizam o desenvolvimento, mas pondera que: "não são as crises que são inevitáveis, mas o momento crítico, a ruptura, as mudanças qualitativas no desenvolvimento" (p.67). A crise seria a prova de que um momento crítico ou uma mudança não se deu em tempo: "não ocorrerão crises se o desenvolvimento psíquico da criança não tomar forma espontaneamente e, sim, se for um processo racionalmente controlado, uma criação controlada.” (p.67).

Embora não seja possível aqui analisar as implicações pedagógicas da perspectiva históricodialética do desenvolvimento infantil, não podemos deixar de destacar o papel do professor, entendido por Leontiev como aquele que deve dirigir ou controlar racionalmente o processo de desenvolvimento da criança. Cabe esclarecer que a idéia de uma criação controlada, conforme preconiza o autor, em nada se aproxima de um processo que supostamente cercearia

5 Nos textos de Elkonin a que temos acesso em língua portuguesa, inglesa ou espanhola, o autor apenas menciona a existência de fases no interior dos períodos, sem, contudo, apresentar e discutir o conceito. a criatividade, iniciativa e liberdade da criança. Leontiev (2001) defende que o professor conheça profundamente o processo de desenvolvimento infantil e suas forças motrizes, para que possa estabelecer finalidades e objetivos pedagógicos adequados e organizar atividades de ensino que promovam o desenvolvimento da criança, ou, nas palavras de Elkonin, que produzam o novo no desenvolvimento infantil. Em relação aos períodos de ruptura e salto qualitativo no desenvolvimento, cabe ao professor apresentar novas tarefas e exigências que correspondam às potencialidades em mudança da criança e a sua nova percepção da realidade.

\section{CONSIDERAÇÕES FINAIS}

Os estágios do desenvolvimento descritos pelos autores, como vimos, possuem certa seqüência no tempo, mas não são imutáveis, na medida em que as condições histórico-sociais exercem influência tanto sobre o conteúdo concreto de um determinado estágio do desenvolvimento quanto sobre o curso do processo como um todo. Como deixou claro Leontiev (2001), os períodos descritos referem-se às condições histórico-sociais da União Soviética do início do século XX, sendo incoerente com os próprios pressupostos da obra dos autores transferi-los de modo linear e imediato para nossa realidade. É evidente que o trabalho realizado por esses autores pode nos auxiliar na compreensão de nossa própria realidade, mas cabe a nós, psicólogos e pesquisadores contemporâneos, a tarefa de analisar o desenvolvimento infantil que se produz em nosso momento histórico, sob nossas condições sociais. Vigotski, Leontiev e Elkonin já nos deixaram o ponto de partida, instigando-nos a investigar o desenvolvimento infantil como um complexo processo dialético que é historicamente determinado e se processa não pela via evolutiva, mas pela via revolucionária.

\section{REFERÊNCIAS}

Bock, A. M. B. (2000). As influências do Barão de Münchhausen na Psicologia da Educação. Em E. R. Tanamachi, M. Proença, \& M. L. Rocha. (Orgs.), Psicologia e Educação: desafios teóricopráticos (pp.11-34). São Paulo: Casa do Psicólogo.

Davidov, V. (1988). La enseñanza escolar e el desarrollo psiquico. Moscú: Progresso.

Duarte, N. (2000). A anatomia do homem é a chave da anatomia do macaco: a dialética em Vigotski e em Marx e a questão do saber objetivo na educação escolar. Educação e Sociedade, XXII(71), 79-115. 
Elkonin, D. B. (1987). Sobre el problema de la periodización del desarrollo psíquico en la infancia. En V. Davidov. \& M. Shuare. (Orgs.), La psicologia evolutiva e pedagógica en la URSS. URSS: Progresso.

Elkonin, D. B. (1998). Psicologia do jogo. São Paulo: Martins Fontes.

Facci, M. (2004). A periodização do desenvolvimento psicológico individual na perspectiva de Leontiev, Elkonin e Vigotski. Cadernos Cedes, 24(62), 64-81.

Leontiev, A. N. (2001). Uma contribuição à teoria do desenvolvimento da psique infantil. Em L. S. Vigotskii, A. R. Luria \& A. N. Leontiev. Linguagem, desenvolvimento $e$ aprendizagem ( $9^{\mathrm{a}}$ ed.). São Paulo: Ícone.

Kosik, K. (1976). Dialética do concreto. Rio de Janeiro: Paz e Terra.
Marx. K. (1983). O Capital. São Paulo: Abril Cultural.

Piaget, J. (1967). Seis estudos de psicologia. Rio de Janeiro: Forense.

Prado Jr., C. (1969). Dialética do Conhecimento (Vol. 2). São Paulo: Brasiliense.

Vygotski, L.S. (1995). Obras escogidas (Vol. 3). Madrid: Visor.

Vygotski, L.S. (1996). Obras escogidas (Vol. 4). Madrid: Visor.

Vigotski, L.S. (2001). A construção do pensamento e da linguagem. São Paulo: Martins Fontes.

Recebido em 10/08/2007 Aceito em 19/05/2008

Endereço para correspondência : Juliana Campregher Pasqualini. Rua Sebastião Pregnolato, 6-70, apto 14-D, CEP 17047-145, Bauru-SP, Brasil.E-mail: jupasqualini@uol.com.br 